\title{
Impact of COVID-19 on Performance of Pakistan Stock Exchange
}

\author{
Author Name: Shehar Yar Ahmed \\ Affiliation: Suleman Dawood School of Business - Lahore University of Management \\ Sciences \\ Lahore, Pakistan; Email Address: Sheharyar.ahmad@lums.edu.pk \\ Cell Number: +923044787679
}




\section{ABSTRACT}

The objective of this study is to determine the impact of COVID-19 on the performance of Pakistani Stock Market. This study uses the data of COVID-19 related positive cases, fatalities, recovers and the closing prices of PSX 100 index of the first half of 2020. The findings of the study suggest that only COVID-19 recoveries are influencing the performance of the index and the daily positive cases and fatalities are insignificantly related to the performance. Further studies can be performed by incorporating other variables such as economic growth, interest rate and inflation rate along with the COVID-19 related variables at a cross-country level.

Keywords: COVID-19 and Stock Market, Pakistan Stock Market and Pandemic, Financial Markets and Pandemics. 


\section{TABLE OF CONTENTS}

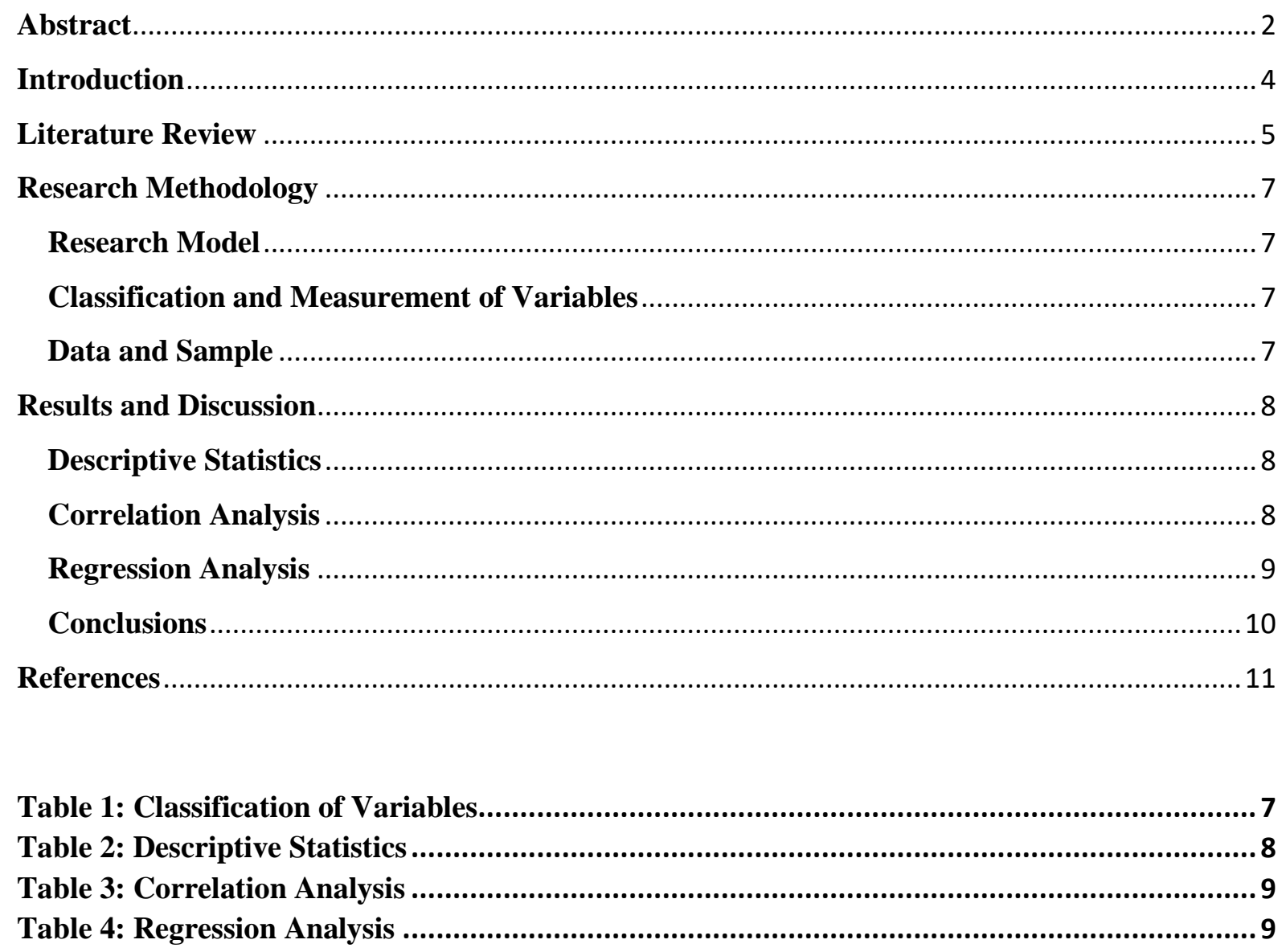




\section{INTRODUCTION}

The infectious disease of Novel Coronavirus (2019-nCOV) or COVID-19 first emerged in December 2019 in Wuhan City, Hubei Province of China (WHO, 2020). It quickly got the attention of the world due to its vast spread in January 2020 due to its quick spread compared to the other kinds of coronaviruses. The response of Chinese government towards the new virus was the complete lockdown of the epicentre of the diseases, the Wuhan city which later proved as an effective measure of controlling the pandemic at large in various countries of the world. The entire city was put under lockdown as an attempt to stop the spread of the disease on $23^{\text {rd }}$ January 2020 (Guardian, 2020).

After China, South Korea was the second country which faced a major outbreak of COVID-19 and after that as of now, around 9.1 Million positive cases of COVID-19 has been reported worldwide along with 472, 539 global fatalities (Hopkins, 2020). The number of positive cases and fatalities has been rising since the emergence of disease and in some parts of the world the spread has slowed like European regions but in several regions like Americas and Asia, the disease is still spreading at a rapid rate. On 11 March 2020, COVID-19 was declared as a global pandemic by WHO and more than 170 countries are affected as a result of the disease (WHO, 2020).

COVID-19 disease has jolted the global economy and financial markets since the great depression. The preventive measures like social distancing and lock-downs have proved their essence to a greater extent but they have a cost in the form of reduced business sales and even the permanent closure of various entities. The economic losses due to COVID-19 have also affected the global stock markets. The contagion effect of the pandemic on global stock markets have been observed in almost every continent and Pakistani stock market is also one of the exchanges that have been influenced as a result of COVID-19.

The objective of this research is to determine the response of the Pakistani stock market against the COVID-19 pandemic that how the performance of the market was influenced. It has been hypothesized that the performance of Pakistani stock market is influenced as a result COVID19 positive cases, fatalities and recoveries. Findings of the study indicate that only COVID-19 recoveries have influenced the performance of the market and positive cases and fatalities are not relevant in the given case. The fluctuations which have been observed in the Pakistani stock market during the first half of 2020 are subject to some other variables. 
This remaining sectors of the paper have been divided into the following. Section 2 provides a comprehensive review of the literature. Section 3 provides the detail regarding research methodology of the study. Section 4 a discussion on the findings of the study. Section 5 concludes the study with key implications and recommendations.

\section{LITERATURE REVIEW}

Ding, Levine, Lin \& Xie (2020) perform their study regarding corporate immunity during the COVID-19 pandemic. During the first quarter of 2020, they use the data of more than 6,000 firms from 56 countries. They aim to determine the impact of COVID-19 cases on stock prices and corporate characteristics in this case. The findings of the study suggest that the firms with stronger pre-2020 finances, less exposure to the pandemic, less entrenched executives and higher social responsibility activities faced a mild pandemic induced drop in the stock price. Additionally, the findings also tell that the companies having larger corporate ownership did well and companies having higher ownership of hedge funds did worst in terms of performance.

Alfaro, Chari, Greenland \& Schott (2020) presents a real-time analysis of firm-level stock and aggregate returns during the COVID-19 pandemic. They attempt to explain the unexpected changes that are occurring in the COVID-19 trajectory infections are predicting the returns of the US stock market. Based on a sample of 4, 070 firms listed in the United States and taking data from Yahoo Finance and Bloomberg, the parameter estimates indicate that if the projected infections are doubled the next day aggregate US market returns are decreased and vice-versa. The findings suggest that the COVID-19 related market losses rise with leverage and capital intensity. The losses are much deeper in the companies or industries which are highly conducive for disease transmission.

Amore, Pelucco \& Quarato (2020) in their study analyse the family ownership during the COVID-19 pandemic. They test how the inclusion of families in governance and ownership affects the financial performance of the companies. The sample of the study has been selected from Italian firms during the spread of COVID-19. The findings suggest that the firms having controlling shareholders on their boards performed better during the pandemic compared to the others.

Corbet, Larkin \& Lucey (2020) in their study examine the contagion effect of the COVID-19. They propose that the Chinese financial markets since the beginning of the COVID-19 pandemic served the role of the epicentre of both financial and physical contagion. During the 
period analysed, the findings of the study indicate a large number of expected characteristics during a "flight to safety". During the period of the enormous financial crisis, the relationship between Bitcoin and Chinese stock markets have eventually evolved.

Schoenfeld (2020) in his study assess the factor of risk in the context of financial markets and pandemics. The study uses COVID-19 pandemic as a natural experiment to determine how financial markets respond to the large scale pandemics. The findings indicate that the managers underestimate the pandemic-related risk compared to the SEC-mandated risk factors and consequently a decline in the value of firms in this regard. The findings also suggest that to the financial markets and their performance, pandemics are systematically being important.

Ruiz Estrada, Koutronas \& Lee (2020) analyse the financial and economic impact of the COVID-19 pandemic. An analytical model has been formulated in this study which helps to understand the patterns of spatiotemporal of occurrence of COVID-19 type of disease and its implications and relevance towards the financial markets. The paper introduces a novel multidimensional geometric approach and the concept of stagpression in the given scenario of epidemics.

Ashraf, Rizwan \& Ahmad (2020) analyse in their study the impact of Islamic Equity Investments (IEIs) during the COVID-19 pandemic. It has been reported by S\&P Down Jones that during the first quarter of 2020 the IEIs continued to outperform their conventional counterparts. This claim has been made due to the stringent handling of the IEIs and the potential hedging benefits exercised. The findings provide evidence that hedging benefits are provided by IEIs during the market downfall and the study suggest that hedging benefits come at an additional cost.

Hence, based on the above literature review the following hypotheses have been suggested:

Ho1: The performance of Pakistani stock market is not influenced as a result of COVID-19 fatalities.

Ho2: The performance of Pakistani stock market is not influenced as a result of COVID-19 positive cases.

Ho3: The performance of Pakistani stock market is not influenced as a result of COVID-19 recovered cases. 


\section{RESEARCH METHODOLOGY}

This section addresses the methodology used in the study in the context of data and sample, research model and classification of variables in the following headings:

\section{RESEARCH MODEL}

The objective of this study is to determine the impact of COVID-19 on the performance of Pakistani stock market. The research model of this study has been presented as follows:

$$
\text { PRICE }_{i t}=\alpha+\beta_{1} \text { POSITIVE } E_{i t}+\beta_{2} \text { FATAL }_{i t}+\beta_{3} R E C O V E R_{i t}+\varepsilon_{i t}
$$

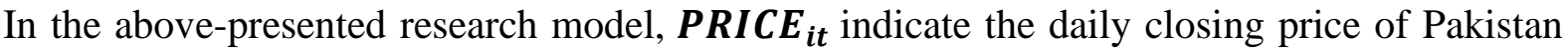
Stock Exchange, POSITIVE $\boldsymbol{E}_{i t}$ indicates the daily number of positive COVID-19 cases, $\boldsymbol{F A T A L _ { i t }}$ indicates the daily number of COVID-19 fatalities, RECOVER $\boldsymbol{R}_{i t}$ indicates the number of daily COVID-19 recovers and $\boldsymbol{\varepsilon}_{\boldsymbol{i}}$ denotes the error term.

\section{CLASSIFICATION AND MEASUREMENT OF VARIABLES}

The variables of this study are classified in the following table:

\begin{tabular}{|c|c|c|}
\hline Name & Type & Measurement \\
\hline$P R I C E_{i t}$ & Dependent Variable & It is measured by the daily closing price of the index. \\
\hline POSITIVE & Independent Variable & It is measured by the frequency of daily positive cases. \\
\hline FATAL $L_{i t}$ & Independent Variable & It is measured by the frequency of daily fatal cases. \\
\hline RECOVER $R_{i t}$ & Independent Variable & It is measured by the frequency of daily recovered cases. \\
\hline
\end{tabular}

TABLE 1: ClassificATION OF VARIABLES

\section{DATA AND SAMPLE}

The data of the study has been obtained from two different sources. The daily closing prices of the index have been obtained from the PSX (Pakistan Stock Exchange) data portals. The information of COVID-19 cases has been obtained from the official portal of Government of Pakistan regarding COVID-19. The data of the first half of 2020 has been obtained on a daily basis from these sources. 


\section{RESULTS AND DISCUSSION}

The results obtained with the help of data analysis are explained in the following sections by using descriptive statistics, correlation analysis and regression analysis.

\section{DESCRIPTIVE STATISTICS}

According to the descriptive statistics, it can be observed that the average price of PSX 100 index has remained 25, 473.61 points during the first half of 2020. The average number of positive cases during the first of 2020 is 26,317 , the average number of fatal cases is 531 and during the same period of time, the average recoveries are 9, 273 on daily basis. During the first half of 2020, the maximum index price was 30,058 points where the minimum index price was 20, 044. The maximum number of positive cases during the first half are 192, 970 and that of fatal cases and recoveries is 3903 and 81, 307, respectively. During the first half of 2020, the lowest index price was 20,044 and this analysis has been drawn on the basis of 119 observations.

\begin{tabular}{|c|c|c|c|c|}
\hline Descriptive Statistic & CLOSING_PRICE & POSITIVE & FATAL & RECOVER \\
\hline Mean & 25473.61 & 26316.62 & 530.6891 & 9272.882 \\
\hline Median & 24614.02 & 1197.000 & 9.000000 & 75.00000 \\
\hline Maximum & 30058.45 & 192970.0 & 3903.000 & 81307.00 \\
\hline Minimum & 20043.89 & 0.000000 & 0.000000 & 0.000000 \\
\hline Std. Dev. & 2812.642 & 48820.80 & 969.3377 & 18644.43 \\
\hline Skewness & 0.140655 & 2.088992 & 2.029747 & 2.309369 \\
\hline Kurtosis & 1.869991 & 6.302375 & 6.119680 & 7.489388 \\
\hline Observations & $\mathbf{1 1 9}$ & $\mathbf{1 1 9}$ & $\mathbf{1 1 9}$ & $\mathbf{1 1 9}$ \\
\hline
\end{tabular}

TABLE 2: DESCRIPTIVE STATISTICS

\section{CORRELATION ANALYSIS}

The correlation analysis based on the following table indicates that there is a negative correlation between the closing price of the index and the number of fatal, positive and recovered cases. The correlation between closing price, fatalities, recoveries and positive cases are significant at a level of $5 \%$ significance. 


\begin{tabular}{|c|r|r|r|r|}
\hline \multicolumn{5}{|c|}{ Correlation Analysis } \\
\hline Correlation/Probability & CLOSING_PRICE & FATAL & RECOVER & POSITIVE \\
\hline CLOSING_PRICE & 1.000000 & & & \\
\hline & ----- & & & \\
\hline FATAL & -0.225796 & 1.000000 & & \\
\hline RECOVER & 0.0135 & ----- & & \\
\hline & -0.198355 & 0.994363 & 1.000000 & \\
\hline POSITIVE & 0.0306 & 0.0000 & ----- & \\
\hline & -0.223726 & 0.999264 & 0.995735 & 1.000000 \\
\hline
\end{tabular}

TABLE 3: CORRELATION ANALYSIS

\section{REGRESSION ANALYSIS}

The regression analysis of the study has been performed in the following table which indicates that there is a negative and insignificant relationship between PSX 100 price movement and the number of fatal COVID-19 cases. Secondly, there is a positive and significant relationship between PSX 100 price movement and the number of recovered cases. Thirdly, there is a negative and insignificant relationship between PSX 100 index price movement and the number of positive cases in this regard. The coefficient of determination, in this case, is 0.1202 which means only $12.02 \%$ of the variation in the dependent variable is explained by independent variables which state that the model is not a good fit. The presence of serial correlation in residuals is validated by the Durbin-Watson statistic as it is less than 2.00.

\begin{tabular}{|c|r|r|r|r|}
\hline \multicolumn{5}{|c|}{ Regression Analysis } \\
\hline Variable & Coefficient & Std. Error & t-Statistic & \multicolumn{1}{|c|}{ Prob. } \\
\hline FATAL & -0.816312 & 6.728477 & -0.121322 & 0.9036 \\
\hline RECOVER & 0.429584 & 0.145417 & 2.954151 & 0.0038 \\
\hline POSITIVE & -0.160050 & 0.153534 & -1.042439 & 0.2994 \\
\hline C & 26135.30 & 300.1615 & 87.07081 & 0.0000 \\
\hline R-squared & 0.120213 & Mean dependent var & 25473.61 \\
\hline Adjusted R-squared & 0.097262 & S.D. dependent var & 2812.642 \\
\hline S.E. of regression & 2672.362 & Akaike info criterion & 18.65235 \\
\hline Sum squared resid & $8.21 E+08$ & Schwarz criterion & 18.74576 \\
\hline Log likelihood & -1105.815 & Hannan-Quinn criter. & 18.69028 \\
\hline F-statistic & 5.237836 & \multicolumn{2}{|c|}{ Durbin-Watson stat } & 0.049471 \\
\hline Prob(F-statistic) & 0.002003 & \multicolumn{3}{|}{} \\
\hline
\end{tabular}

TABLE 4: REGRESSION ANALYSIS 
Hence, based on the above regression analysis, we fail to reject the null hypotheses that the performance of Pakistani stock market is influenced by COVID-19 fatalities and positive cases. Although, the findings suggest that the performance of Pakistani stock market is influenced due to COVID-19 related recoveries. The fluctuating trend of performance of PSX 100 index during the first half of the year 2020 can be due to some other reasons and the findings suggest that the pandemic-related information has little to do with the performance of a stock market in South Asian perspective.

\section{CONCLUSIONS}

The objective of this study was to determine the impact of COVID-19 on the performance of Pakistani stock market and to the best of my knowledge, it is one of the few studies exploring the relationship of COVID-19 and the performance of the stock market. The study hypothesized that the performance of Pakistani stock market is influenced as a result of COVID-19 positive cases, fatalities and recoveries. The findings of the study suggest that only COVID-19 recoveries are a strong predictor of the performance of the stock market and positive cases and fatalities have a non-significant relationship with the performance of the market. Further studies can be performed by incorporating other variables such as economic growth, interest rate and inflation rate along with the COVID-19 related variables at a crosscountry level. Hence, a clear description of the pandemic-related variables can be ascertained affecting the performance of a stock market in this regard. 


\section{REFERENCES}

Alfaro, L., Chari, A., Greenland, A. N., \& Schott, P. K. (2020). Aggregate and firm-level stock returns during pandemics, in real-time (No. w26950). National Bureau of Economic Research. Amore, M. D., Pelucco, V., \& Quarato, F. (2020). Family Ownership During the Covid-19 Pandemic.

Ashraf, D., Rizwan, M. S., \& Ahmad, G. (2020). Islamic Equity Investments and the COVID19 Pandemic. Available at SSRN 3611898.

Corbet, S., Larkin, C., \& Lucey, B. (2020). The contagion effects of the COVID-19 pandemic: Evidence from gold and cryptocurrencies. Finance Research Letters, 101554.

Ding, W., Levine, R., Lin, C., \& Xie, W. (2020). Corporate immunity to the COVID-19 pandemic (No. w27055). National Bureau of Economic Research.

Guardian, T.. (2020, January 23). Coronavirus: panic and anger in Wuhan as China orders city into lockdown. Retrieved from The Guardian: https://www.theguardian.com/world/2020/jan/23/coronavirus-panic-and-anger-in-wuhan-aschina-orders-city-into-lockdown

Hopkins, J. (2020, June 23). COVID-19 Dashboard by the Center for Systems Science and Engineering (CSSE) at Johns Hopkins University (JHU). Retrieved from John Hopkins University of Medicine: https://coronavirus.jhu.edu/map.html

Ruiz Estrada, M. A., Koutronas, E., \& Lee, M. (2020). Stagpression: The economic and financial impact of Covid-19 Pandemic. Available at SSRN 3593144.

Schoenfeld, J. (2020). The invisible risk: Pandemics and the financial markets. Available at SSRN 3567249.

WHO. (2020). Coronavirus disease 2019 (COVID-19) Situation Report - 51. World Health Organization. Retrieved from https://www.who.int/docs/defaultsource/coronaviruse/situation-reports/20200311-sitrep-51-covid-19.pdf?sfvrsn=1ba62e57_10 WHO. (2020). Novel Coronavirus (2019-nCoV) Situation Report - 1. World Health Organization. $\quad$ Retrieved from https://www.who.int/docs/defaultsource/coronaviruse/situation-reports/20200121-sitrep-1-2019-ncov.pdf?sfvrsn=20a99c10_4 


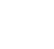

